\title{
IL13-induced lung fibrosis in meconium aspiration
}

\author{
Alexander Zagariya ${ }^{1 *}$, Shangaral Navale ${ }^{2}$, Olga Zagariya ${ }^{3}$, Kenneth McClain ${ }^{4}$, \\ Dharmapuri Vidyasagar ${ }^{2}$ \\ ${ }^{1}$ Cancer Center at the University of Illinois at Chicago, Chicago, USA; \\ ${ }^{2}$ Department of Cardiology, Northwestern University at Chicago, Chicago, USA; \\ ${ }^{3}$ Department of Pediatrics, the University of Illinois at Chicago, Chicago, USA; \\ ${ }^{4}$ Texas Children's Cancer Center/Hematology Service to Baylor College of Medicine, Houston, USA. \\ Email: *zagariya@uic.edu
}

Received 16 May 2011; revised 26 June 2011; accepted 10 July 2011.

\begin{abstract}
We demonstrated previously that inflammatory cytokines TNF $\alpha$, IL1 $\beta$, IL6 and IL8 are significantly expressed in meconium-instilled lungs. Captopril was a strong inhibitor of meconium-induced lung injury, inflammation and apoptosis and reduces lung alveolar and airway epithelial cell damage. Presently we demonstrate that IL13 expression in the meconium aspiration syndrome (MAS). IL13 was maximally expressed $8 \mathrm{hrs}$ after meconium instillation. It was previously described that IL13 plays a major role in degradation of airway epithelial cells and inducing of lung fibrosis by activating collagen production that is a major point in identification of lung fibrosis. We also showed that Captopril treatment significantly inhibits IL13 expression in the lungs. We believe it reduces meconium-induced lung injury and has a therapeutic effect on histological and biochemical functions of the lungs and possibly pulmonary fibrosis. Captopril treatment significantly reduced the number of neuprophils and macrophages which express IL13 and levels of other inflammatory cytokines after meconium instillation. Selective neutralization of IL13 ameliorated lung injury, airway hyper responsiveness, eosinophil recruitment and mucus overproduction.
\end{abstract}

Keywords: Meconium Aspiration Syndrome; IL13 Cytokine; Newborn Lungs; Fibrosis

\section{INTRODUCTION}

Meconium aspiration syndrome (MAS) causes inflammation of airways and an inappropriate immune response with elevated levels of TNF $\alpha$, IL1 $\beta$, IL6 and IL8 inflammatory cytokines expression [1]. Lung disease severity directly correlates with progressive inflammation of the alveoli and airways which induce airway ob- struction and cell apoptosis. We studied a meconiuminduced lung injury in isolated perfused rat lungs exposed to anoxia [2]. We also demonstrated that inflammatory response in meconium-instilled lungs [3] resulted in apoptotic cell death [4,5]. Lung cell response and injury to inflammation is mediated via induction of cytokines. Meconium in the lungs induces multiple cytokine systems expression including TNF $\alpha$, IL1 $\beta$, IL6, IL8, IL10, IL13 and other cytokines. From these IL10 and IL13 are anti-inflammatory cytokine and others proinflammatory cytokines. Proinflammatory cytokines in MAS have been studied extensively. However, the role of anti-inflammatory agents, including IL13, have not been studied. Its role for inducing a lung fibrosis is well known, however, its presence in MAS was not demonstrated before [9].

In our previous work we demonstrated that apoptotic cell death can be effectively attenuated by treatment with Captopril [6]. We also determined that angiotensin II (ANG II) plays a major role in meconium-induced apoptosis [7] and its inhibitors like Losartan (inhibitor of ANG II-AT1 receptors) dramatically decreases apoptotic cell death [8]. Despite these findings the exact mechanism of meconium-induced lung cell apoptosis remains unclear.

Expression of IL13 receptors has been shown in variety of immune and nonimmune cells including B cells, natural killer cells, monocytes, mast cells, endothelial cells and fibroblasts [10-12], but not in T cells [3]. The potent spasmogenic properties of IL13 have identified this molecule as a potential regulator of airway hyper reactivity in asthma and in emphysema [14]. It enhanced lung volumes and contributed to decreased compliance, mucus metaplasia and inflammation. The effect of IL13 is similar to IL4. Both cytokines activate the JAK2 tyrosine-dependent signal transduction pathway [12]. Both are located on human chromosome 5q25-31 [15] induce activation of pulmonary fibroblasts [9] and mononuclear 
cells and macrophages [16]. Specifically, IL13 induces fibroblast proliferation in the lungs $[9,17]$ and liver [18]. IL13 enhances generation of other inflammatory cytokines and chemokines (such as TNF $\alpha$ and IL6) inhibitors of IL13 or (IL13Ra2), markedly attenuated granuloma development, pulmonary eosinophilia and pulmonary fibrosis.

To induce injury IL13 should bind to its cell surface receptor [19]. By blocking IL13 binding to its receptors cell injury is significantly decreased. It was shown that by blocking the IL13 receptor with IL13PE (IL13 immunotoxin) fibroblast proliferation decreased by about $30 \%$ [20]. Expression of IL13 induces significant collagen type 1 and 2 production in fibroblast cell lines demonstrate a higher degree of proliferation [20]. We propose that limiting the exposure of lung cells to IL13 will significantly limit or reduce the degree of lung injury and fibrosis [20].

\section{MATERIALS AND METHODS}

Meconium preparation. 10\% meconium preparation and cell death analysis were performed as described by us earlier [5].

Pretreatment with Captopril. Two week old rabbits were pretreated with $500 \mathrm{mg} / \mathrm{L}$ Captopril in their drinking water 48 hrs prior to meconium instillation as described previously [6].

Pretreatment with Losartan. Another group of rabbits received two days of pretreatment with Losartan (an AT1 receptor binding agent and inhibitor which inhibits production of ANG II and consequently apoptosis) in the rabbit chow targeted to approximate (by food consumption) $5.0 \mathrm{mg} / \mathrm{kg} /$ day as described earlier [8].

Lung lavage. Rabbits were euthanized and lungs were isolated. Lung lavage was obtained from the left lung and the right lung was used for immunohistochemistry. The left lung was cannulated and removed, and right lung was instilled with $10 \mathrm{ml} 1 \times$ PBS and lavage was collected immediately. The procedure was repeated 5 times and all lung lavage collections were pooled. Lavage cells were disrupted by freeze-thawing procedure and then where centrifuged at 5000 RPM for 5 min at $4^{\circ} \mathrm{C}$ to separate cell debris. Then supernatants were collected and stored at $-70^{\circ} \mathrm{C}$. The levels of IL13 were determined immunologically using an ELISA kit (R\&D Systems Inc., Minneapolis, MI) according the manufacturers instructions. Lung lavage cell death was counted after staining of cells by ethidium bromide and acrydine orange as described previously [5].

Lung histology. Rabbits were instilled intratracheally with $10 \%$ meconium or normal saline and were sacrificed 8 hrs after instillation. Following anesthesia-induced euthanasia, the right lungs from meconium-instilled rab- bits were separated and fully inflated with $4 \%$ formalin, dissected, and placed in fresh formalin for 24 hrs. Routine histological techniques were used to paraffin-embed the entire lung, and $2 \mu \mathrm{m}$ sections of whole lung were stained with H\&E. Each whole lung from the meconium treatment group was examined for the presence of inflammatory infiltrates and interstitial fibrosis 8 hrs after meconium instillation and graded with a previously described scale [21]. For this purpose, $10 \%$ meconium was instilled intratracheally into rabbit pups lungs and then rabbits were sacrificed 8 hrs after instillation.

Immunohistochemistry. Paraffin-embedded whole lung samples were analyzed for immunohistochemical localization of IL13. This procedure was used for the detection of IL13 expression in whole lung samples because of a growing concern that the ELISAs may underestimate IL13 actual levels in the lungs. Two micron sections were dewaxed with xelene, rehydrated in graded concentrations of ethanol, and blocked with normal rabbit serum (Vectastain ABC-AP kit; Vector Laboratories, Burlingame, CA). A solution containing a 1/1 ratio of water to methanol with $3 \%$ hydrogen peroxide was added to each slide to be stained for the presence of IL13. Goat anti rabbit IL13 and a control normal goat IgG were diluted in PBS to a final concentration of $2 \mu \mathrm{g} / \mathrm{ml}$. Specific IgG were added to histological sections for 60 min, after which each tissue section was washed thoroughly three times with PBS. A secondary rabbit anti-goat biotinylated antibodies (Vector Laboratories, Burlingame, CA) were also added to each section for 60 min, then each slide was thoroughly washed and to each was added alkaline phosphatase (Vector Laboratories, Burlingame, CA) conjugated to avidin. IL13 cytokine was revealed with an alkaline substrate, 5-bromo-4chloro-3-indolyphosphate/nitro blue tetazolium. Cover slips were applied to each slide using an aqueous mounting solution. As positive IL13 control we used human LCH tissue. As negative IL13 control—normal skin.

ELISA analysis. Rabbit IgG anti-IL13 monoclonal antibody was coated on a 96 well plate overnight at $4^{\circ} \mathrm{C}$, then serially diluted samples, or serial dilutions of IL13 used as a standard for $1 \mathrm{hr}$ at $37^{\circ} \mathrm{C}$. Detection was performed using a polyclonal biotinylated goat anti-rabbit IL13 antibody from R\&D systems (Minneapolis, MN), according their instructions) for $1 \mathrm{hr}$ at $37^{\circ} \mathrm{C}$.

The detailed technique for measurement of IL13 cytokine in $50 \mu \mathrm{l}$ samples was described earlier [22]. Cell samples were prepared from whole lung samples homogenized in $2 \mathrm{ml}$ of PBS immediately before ELISA. Each ELISA was screened to ensure antibody specificity. Recombinant cytokines were used to generate the standard curves for ELISA from which the concentrations 
present in the samples were calculated. The limit of ELISA detection for each cytokine was consistently more then $50 \mathrm{pg} / \mathrm{ml}$. The cytokine levels in each sample were normalized to total protein levels measured by the Bradford Assay.

PCR analysis. IL13 gene expression was analyzed by a real-time quantitative PCR procedure (Applied Biosystems, Foster City, CA). The cDNAs from lung lavage samples before and at various times after meconium instillation were analyzed for IL13 and GAPDH (an internal control). All primers and probes used were purchased from Applied Biosystems (Foster City, CA). Cytokine gene expression was normalized to GAPDH, and the fold increases in IL13 gene expression was calculated via the comparison of gene expression in all meconiuminstilled lungs with that in lungs instilled by normal saline.

PCR conditions: PCR amplifications were conducted on a robocycler gradient 96 (Stratagene) in a $30 \mu \mathrm{l}$ reaction containing $100 \mathrm{ng}$ of DNA, $10 \mathrm{mM}$ Tris-HCl, pH9, 0.1\% Triton X-100, $50 \mathrm{mM} \mathrm{KCl,} 0.2 \mathrm{mg} / \mathrm{ml}$ BSA, 1.5 $\mathrm{mM} \mathrm{MgCl} 2,1 \mu \mathrm{M}$ f each primer, $1 \mathrm{mM}$ of $\mathrm{dNTP}$ and 1.5 $\mathrm{U}$ of Taq polymerase (Appligene Biosystems, Foster City, CA). Following the initial denaturation step $\left(94^{\circ} \mathrm{C}\right.$, $5 \mathrm{~min}$ ), samples were subjected to 35 cycles of PCR consisting of $94^{\circ} \mathrm{C}$ for $1 \mathrm{~min}$, annealing temperature for $45 \mathrm{~s}$ and $72^{\circ} \mathrm{C}$ for $45 \mathrm{~s}$.

The PCR analysis for IL13 was previously described by Graves et al. [42]. A 236-bp PCR fragment of IL13 cytokine was generated with use of the primers 5'-GCAAATAATGAGCTTTCGAAGTTTCAGTGG-3' and 5'CTTCCGTGAGGACTGAATGAGACGGTC-3’. To confirm specificity of obtained fragment restriction analysis were done. The NlaIV restriction enzyme analysis of the
PCR product obtained from subjects bearing the IL13 must have two bands (210 and $26 \mathrm{bp}$ ) on 2\% agarose gel. Loading volume including a loading buffer was $20 \mu \mathrm{l}$ per well, same for all samples.

Statistical analysis. The data analyzed by ANOVA followed. The significance of differences between experimental groups was analyzed using Student's unpaired $t$-test. Values were reported as the mean \pm SEM. Differences in mean values were considered significant if $p<0.05$.

\section{RESULTS}

Changes in IL13 expression after meconium-induced lung fibrosis. We demonstrated by ELISA assays that IL13 protein expression were increased at all times: 2, 4, 8 and 24 hrs after meconium instillation versus saline instillation (Figure 1). The greatest, about five fold, increase in IL13 protein expression compared to basal level was observed 8 hrs after meconium instillation. For a comparison, the expression of other cytokines in meconium-instilled lungs versus saline-instilled lungs is also presented in the Figure 2. The meconium-saline ratios of TNF $\alpha$, IL6, and IL8 were increased significantly in meconium-instilled lungs. TNF $\alpha$ reached maximum at 2 hrs after meconium instillation and IL13, IL6 and IL8 at 8 hrs after meconium instillation. In contrast, IL10 levels did not change significantly in any of the groups studies.

Dependence of IL13 expression from Captopril pretreatment. In present study we determined whether pretreatment with angiotensin converting enzyme, Captopril, will prevent meconium-induced lung fibrosis. Captopril, similarly to Losartan described below did not change the

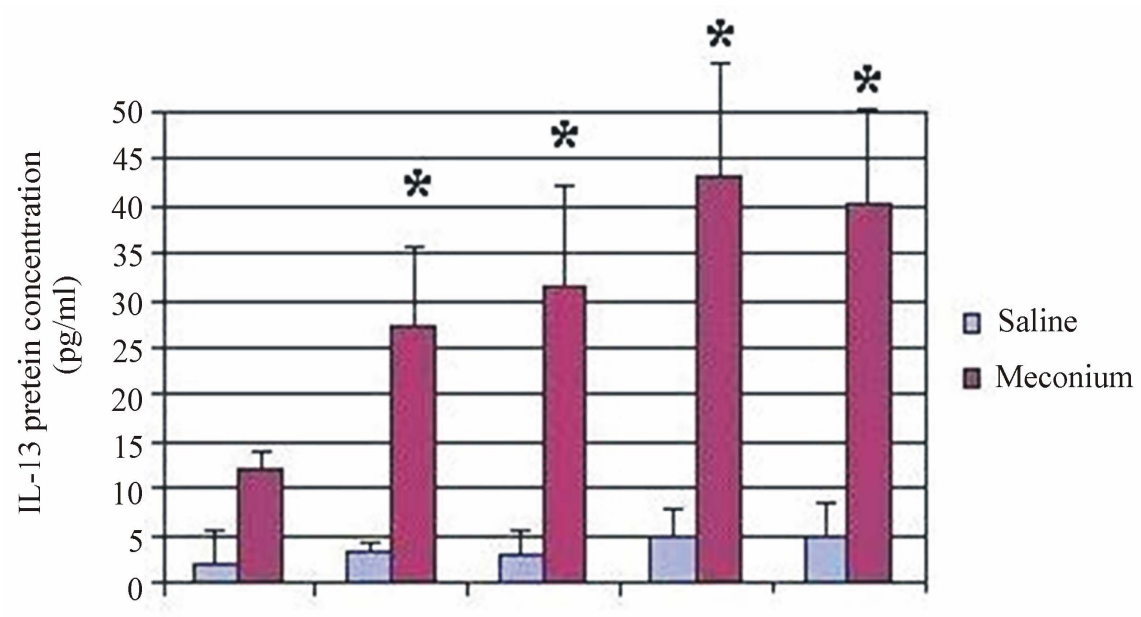

Figure 1. Expresison of IL13 in meconium-and saline-instilled lungs of two week old rabbit pups. In each group of rabbits we used four pups. IL13 was measured at 0, 2, 4, 8 and $24 \mathrm{hr}$ after meconium instillation. Maximum expression was noted at $8 \mathrm{hr}$ after meconium instillation. Data are means \pm SEM. ${ }^{*} p<0.001$ by ANOVA when compared to saline instillation alone. 


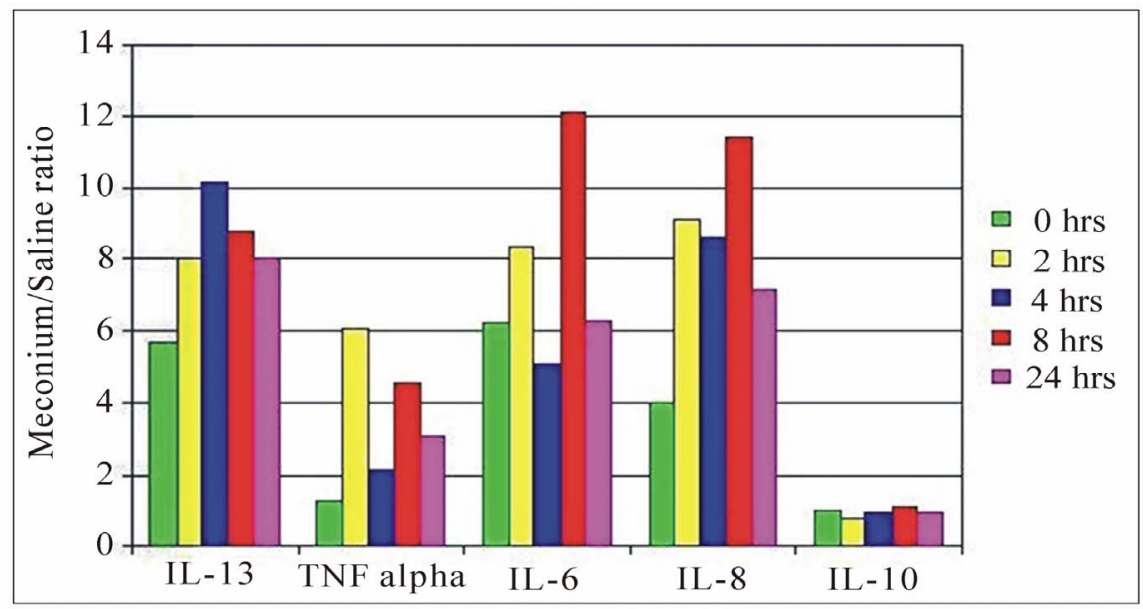

Figure 2. Ratio (meconium/saline) for different cytokines expressed. The expression of each cytokine (pg/ml) was measured by ELISA in lung lavage obtained from meconium and saline-instilled rabbits. Ratio meconium/saline was calculated and presented in this figure. Ratio shows a increased expression of setrain cytokine in meconium instilled lungs compared to saline-instilled lungs.

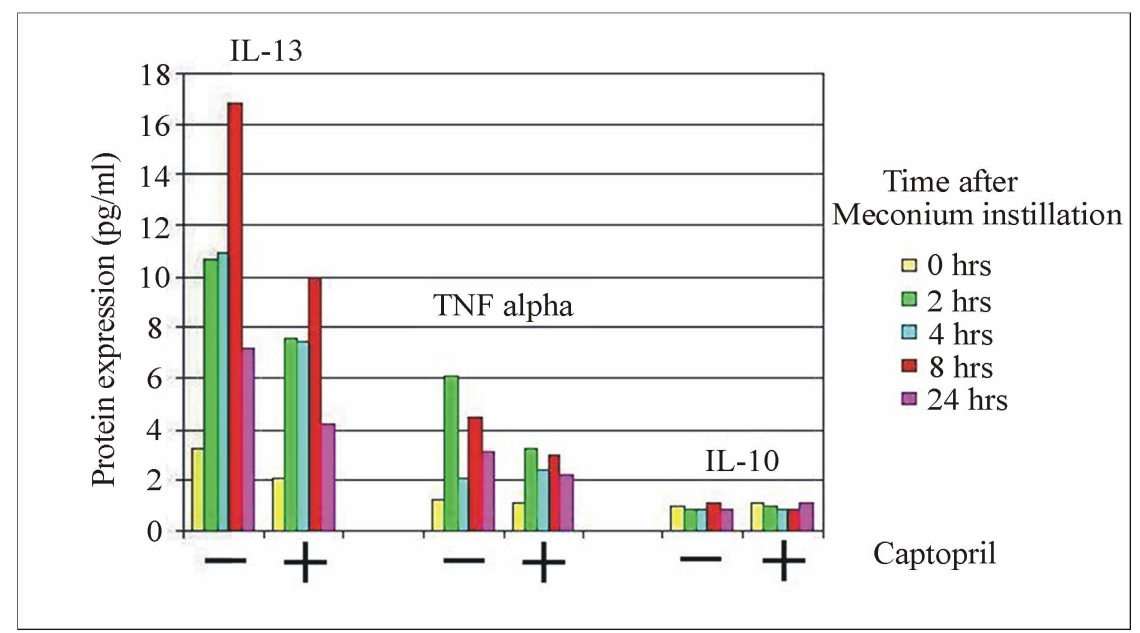

Figure 3. Captopril pretreatment inhibits meconium-induced IL13 and TNF $\alpha$ but not IL10 cytokine expresison. Maximal expression if IL13 in meconium-instilled lungs was noted at $8 \mathrm{hr}$ after meconium instillation. Expression of IL13 was significantly decreased by Captopril treatment. In contrast, maximal expression of TNF $\alpha$ cytokine was seen $2 \mathrm{hr}$ after meconium instillation and also was significantly reduced after Captopril treatment.

histological and immunological picture of the lungs (Figures 3, 7 and 8). Earlier it was demonstrated that Captopril is able to reduce lung cell inflammation, apoptosis [4] and pulmonary fibrosis [24]. Pretreatment of rabbits with Captopril significantly reduced meconium-induced expression of IL13, lung injury, lung apoptosis and fibrosis compared to control rabbits, instilled with normal saline (Figures 3 and 8). Captopril was also able to inhibit expression of other cytokines studied. Immunohistochemical analysis of IL13 in formalin-fixed whole lung samples from meconium-instilled rabbits showed a marked decrease of IL13 in Captopril treated rabbits.
Description of meconium induced lung injury. Meconium-instilled lungs stained by Hematoxylin and Eosin demonstrated a broken alveoli, accumulation of necrotic cells (right side of the Figure 4), hemorrhage and damage of bronchoalveolar alveoli. Alveolar walls of the lungs instilled by meconium were thin, damaged and fewer cells were observed compared to controls. The sacules are not lined by cuboidal epithelium with apical nuclei (progenitor alveolar epithelium). Several protuberances or bungles into the air spaces were noted as well. Also, thinner secondary crests and alveoli are evident. Fewer nuclei are evident in the alveolar walls when 
compared to those of the term controls (Figure 4). Meconium-damaged lungs were analyzed in comparison with saline instilled lungs, published by us previously [4, 5].
Effect of Losartan on IL13 expression in MAS. We further studied an effect of Losartan on IL13 expression. Saline-instilled lungs with or without Losartan pretreatment in immunohistochemical studies did not show

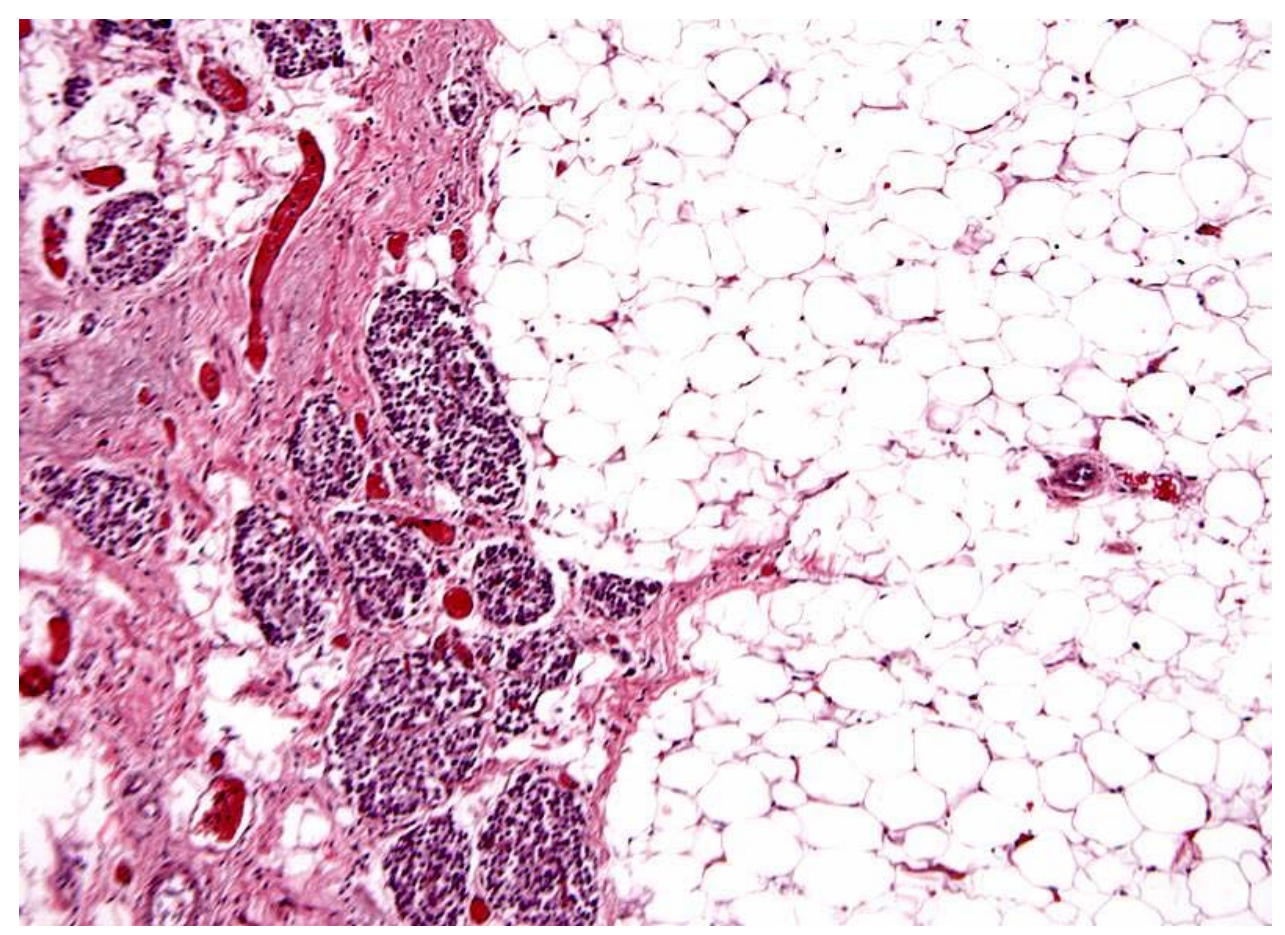

Figure 4. Meconium-induced lung injury. Hematoxylin and Eosin (H\&E) staining revealed brocken alveoli, accumulation of necrotic cells, hemorrhage and damage of bronchioles. Alveolar walls of the lungs from meconium-instilled rabbit lungs were thin, damaged and have fewer cells compared to controls (saline-instilled). The saccules are not lined by cuboidal epithelium with apical nuclei (progenitor alveolar epithelium). Several protuberances or bugles into the air spaces were noted as well. Also, thinner secondary crests and alveoli are evident. Fewer nuclei are evident in the alveolar walls when compared to those of the term controls. Original magnification, $\times 40$. Pictures were analyzed side by side in comparison with normal lungs instilled with normal saline and published by us earlier [4,5].

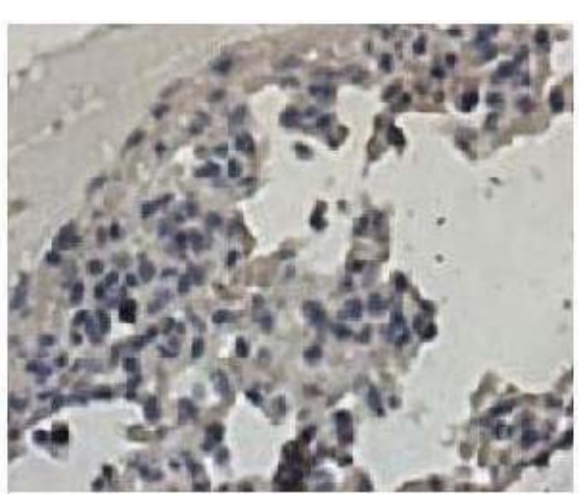

Losartan, Saline

(a)

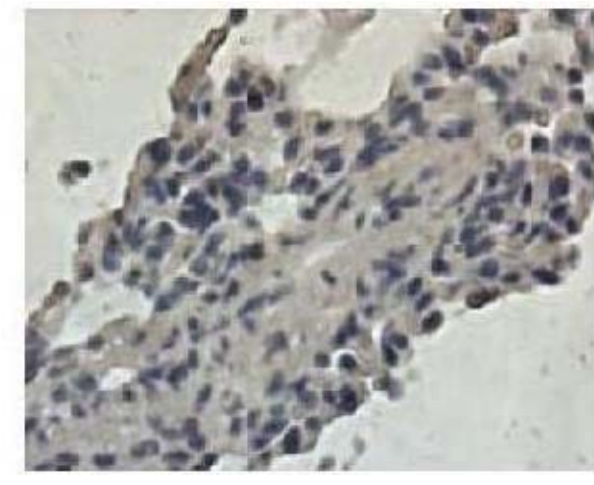

No Losartan, Saline

(b)

Figure 5. Expression of IL13 in saline-instilled rabbits with or without Losartan pretreatment. This figure presented as a control for IL13 staining in presence (a) and absence (b) of Losartan. Details about Losartan pretreatment described in methods above. Note, in both cases IL13 cytokine is not expressed. 
staining for IL13 (Figure 5). However, in meconiuminstilled lungs IL13 expression increased dramatically with a maximum level observed at 8 hrs after meconium instillation (Figures 1 and 6). We determined that BAL IL13 levels were less then or equal to $75 \mathrm{pg} / \mathrm{ml}$ in meconium-treated lungs compared to $20 \mathrm{pg} / \mathrm{ml}$ in saline treated. This expression was markedly attenuated by Losartan. Expression of IL13 was always associated with accumulation of mononuclear cells and macrophages in the lung lavage samples. Specifically, IL13 expression was observed in activated mononuclear cells, airway epithelium cells and fibrotic interstitial areas.

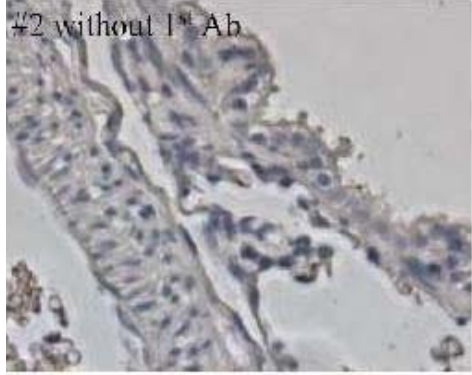

(a)

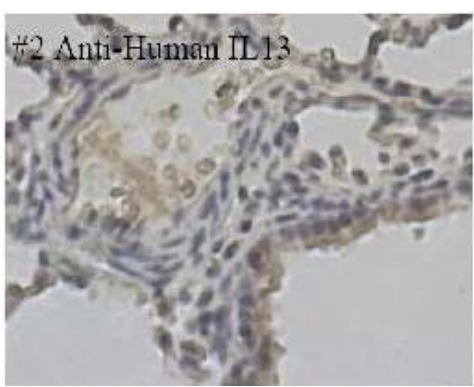

Losartan, Meconium

(c)

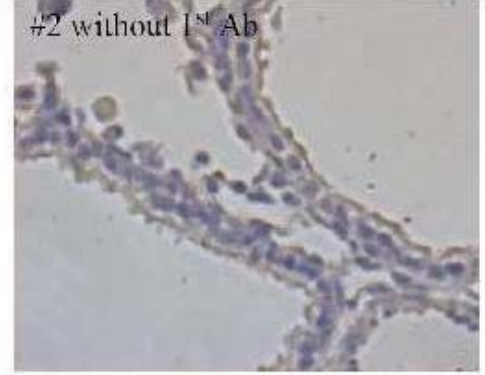

(b)

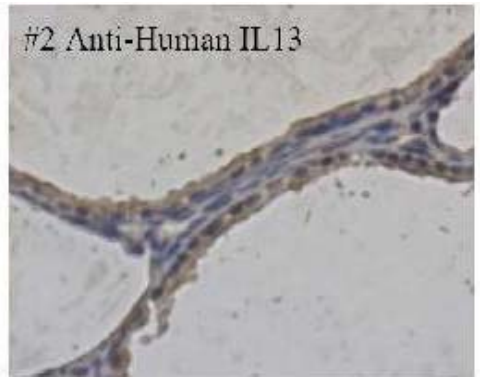

Meconium

(d)

\section{No IL13 antibodies}

IL13 antibodies

Figure 6. Expression of IL13 in meconium-instilled lungs. (a)(c)—Losartan pretreament and then meconium- instilled. (b)(d)—No Losartan, and then meconium-instilled. (a)(b)—No anti-IL13 antibodies. (c)(d) - Anti-IL13 antibodies. Losartan pretreatment (c) abolished meconium-induced IL13 cytokine expression (d).

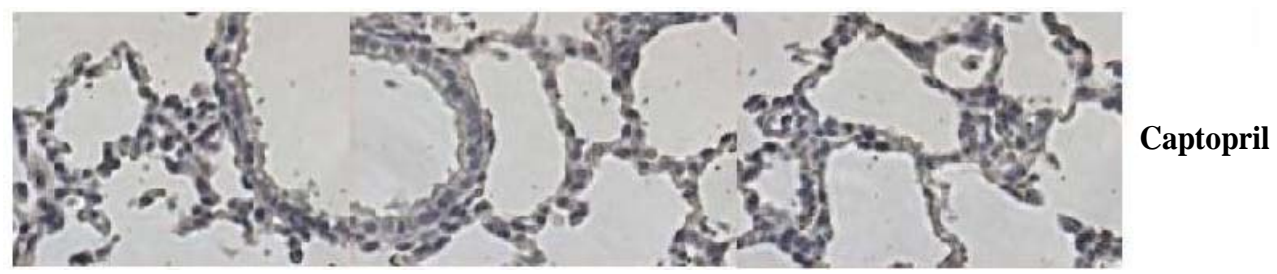

(a)

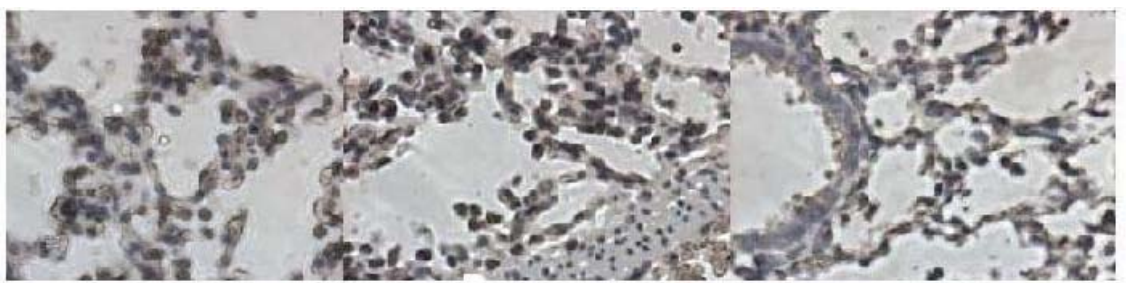

N o Captopril

(b)

Figure 7. Absence of IL13 expression in control lungs with or without Captopril pretreatment. (a) Salineinstilled rabbit lungs after Captopril pretreatment. (b) Saline-instilled rabbits without Captopril pretreatment. Both panels shows no expression of IL13 cytokine. 


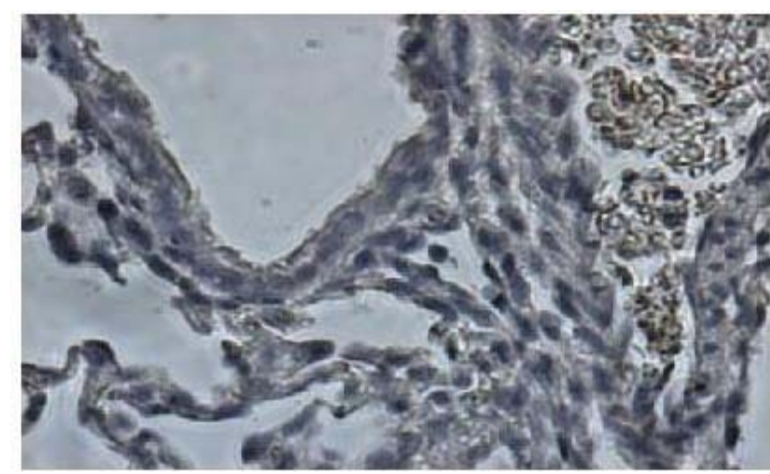

Captopril, Meconium

(a)

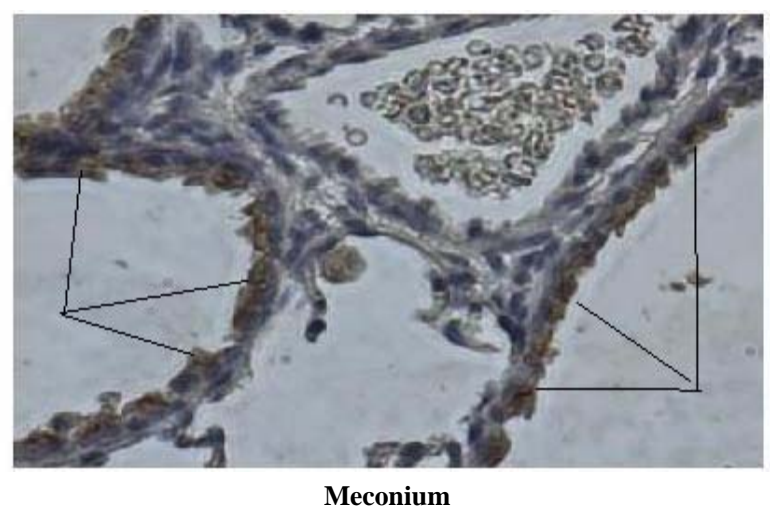

(b)

Figure 8. Captopril pretreatment significantly inhibited meconium-induced IL13 expression. A-Captopril pretreated and then meconium-instilled rabbit lungs. Magnification $\times 40$. Seen much less dark brown staining. B-Maconium-instilled lungs without Captopril pretreatment. Magnification $\times 40$. Seen much higher dark brown staining (please note a marks on the picture which pointed on the strong IL13 expression seen dark brown).

Histological evaluation of IL13 cytokine expression in MAS. Newborn lungs instilled with normal saline did not show any histological abnormalities in presence of Losartan (Figure 5) or Captopril (Figure 7). However, lungs instilled by meconium demonstrate strong expression of IL13 (Figures 4, 6 and 8), followed by inflammatory cell infiltration and lung fibrosis in rabbits. Histological changes were morphologically obvious. We detected enlargement of alevoli with loss of the orderly appearance. IL13-induced lung fibrosis was accompanied with severe damage of bronchial and less damage of vascular or alveolar epithelium. Maximum damage was observed at $8 \mathrm{hrs}$ after meconium instillation and remained at the same level up to $24 \mathrm{hrs}$ after instillation. Inflammation consisted of increased number of macrophages, lymphocytes and eosinophils in peribronchial and parenchyma tissues as well as lavage fluid.

PCR analysis of IL13 cytokine. Figure 9 shows an PCR analysis for IL13 DNA in tracheal aspirates obtained from newborn rabbits instilled intratracheally with: lane 1-Saline, lane 2-Captopril, lane 3-Losartan, lane 4-Meconium, lane 5-Captopril + Meconium, lane 6-Losartan + Meconium, lane 7-NlaIV restriction analysis of the 236 bp IL13 fragment. IL13 is absent in non-inflamatory lungs but highly expressed in meconium-instilled lungs. It's expression can be dramatically inhibited by pretreatment of lungs by Captopril (lane 5) or Losartan (lane 6).

The PCR analysis in 2\% agarose revealed 236 bp IL13 fragments. The NlaIV restriction analysis of the PCR product obtained from subjects bearing the IL13 gives two bands (210 and $26 \mathrm{bp}$ ) on same $2 \%$ agarose gel (Figure 9, lane 7). This analysis confirmed specificity of IL13 PCR fragment obtained. The purification procedure and PCR analysis was controlled by levels of
GAPDH in same samples. Results show, that Captopril or Losartan has virtually no effect on IL13 expression in lung lavage of rabbits after saline instillation. However, meconium-induced rabbit lung demonstrate a dramatic expression of IL13. Densitometry data showed that pretreatment by Captopril inhibits meconium-induced IL13 expression by $85 \%$ compared to $65 \%$ inhibition by Losartan (Figure 9, lanes 5, 6). These data showed that Losartan and especially Captopril are effective inhibitors of IL13 cytokine expression and meconium-induced lung fibrosis.

\section{DISCUSSION}

It has been previously shown that IL13, but not IL4 was a major profibrotic mediator in bleomycin-induced fibrotic mice [16]. However expression of IL13 in meconium-instilled lungs was not previously reported. IL13 was produced more strongly in the lung, then in the heart, liver, stomach, kidney, pancreas or testis [25]. The present study addressed two major aims: 1) to examine the expression of IL13 during development of meconiuminduced lung injury and fibrosis. 2) To determine the role of IL13 responsive cells in the pulmonary fibrotic response via targeting these cells by Captopril. It was noted that IL13 has potential activating effects on monocytes and macrophages that include enhanced IL6, TGF $\beta$, chemokines and chemokines receptors expression [26]. Resident macrophage and recruited monocyte activation is a well-described feature of clinical pulmonary fibrosis $[27,28]$ and these cells contribute to the pathogenesis of pulmonary fibrosis due to bleomycin [29]. IL13 is a potent inducer of collagen production in vivo in the lung [30]. It also was previously shown that IL13 inhibits proteases and degrades the extra cellular matrix [31]. This effect of IL13 is similar to the effect of 


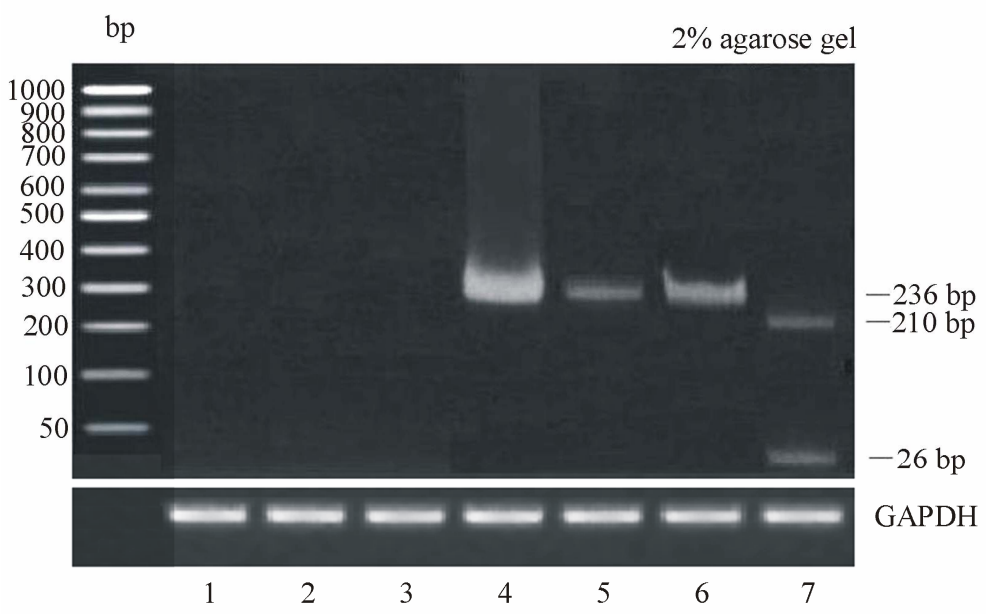

Figure 9. PCR analysis of IL13 cytokine in $2 \%$ agarose gel. bp-1 kb molecular weight marker. Lane 1-Saline, lane 2-Captopril, lane 3-Losartan, lane 4Meconium, lane 5-Captopril + Meconium, lane 6-Losartan + Meconium. Lane 7-The NlaIV restriction analysis of the PCR product obtained from subject bearing the IL13 cytokine gives two bands (210 and 26 bp) on 2\% agarose gel. Note, IL13 cytokine is absent in non-inflamatory lungs. However significantly expressed in meconium-instilled lungs. It's expression can be dramatically inhibited by pretreatment of lungs by Captopril (lane 5) or Losartan (lane 6). Samples preparation and loading control was done by using GAPDH.

protease inhibitors, serpins. A balance of pro- and antifibrotic proteases is critical because excess protease or anti-protease activity has been associated with excessive pulmonary fibrosis induced by the anti-neoplastic drug bleomycin. This imbalance in protease regulation is regulated by the pulmonary fibrotic factors and events. Expression of IL13 is dependent on the activity of extra cellular proteases [30]. Usually an increase of proteinase activities would prevent or reverse the increased deposition of extra cellular matrix and would be associated with lung diseases and inflammation [31].

Recently, IL13 has been identified as a potent regulator of bronchoconstriction in mouse models of asthma [14]. This cytokine is primarily secreted from $\mathrm{T}$ cells but it is also expressed by mast cells, macrophages, eosinophils and NK cells [33-35]. IL13 shares about 30\% homology with IL4 and has similar biological functions. IL13 is a central regulator of mucus production in the lungs.

We found increased IL13 protein in areas of active fibrosis in newborn lung histological sections and its expression peaked 8 hrs after meconium instillation. Immunohistochemistry revealed that IL13 was concentrated preferentially in macrophages and mononuclear cells near or in areas of active fibrosis. This finding was consistent with previous observations that IL13 may be expressed by normal human alveolar macrophages as part of a homeostatic control process, but its production was increased in the presence of fibrotic lung disease
[36]. IL13 has significant impact on the synthetic and proliferative properties of granuloma fibroblasts, but not normal fibroblasts, and the IL13-responsiveness of granuloma fibroblasts renders them targets of IL13based immunotoxin therapy. It also was shown that IL13 is a potent inducer of cysteine proteases production in the lungs [25]. Protease synthesis increases in a dose dependent manner by IL13. As proteases are major destructive agents in the cells. They correlate with increased IL13 expression in meconium-induced lung injury. The levels of mRNA-encoding cysteine proteases have been measured. IL13 also cause an impressive increase in the levels of mRNA encoding cathepsins $\mathrm{B}, \mathrm{H}$, $\mathrm{K}, \mathrm{S}$ and others [25]. Cysteine protease inhibitors such as E-64 or leupeptin decreased expression of IL13. Lung emphysema causes dramatic increases of IL13 expression and promotes an increase in lung volume and lung alveolar size. It also induces significant histological and morphologic changes. These studies demonstrated that cysteine proteases play a major role in the pathogenesis of IL13-induced lung inflammation and later fibrosis. IL13 induced lung enlargement was significantly decreased by treatment with cysteine protease inhibitors and antagonists [25]. To understand the balance of proteases and antiproteases in the lungs the levels of IL13 must be examined. We believe, that IL13 is an important regulator of pulmonary protease and antiprotease balance that can contribute to the patophysiology of MAS.

Previous studies suggest that the deregulation of apop- 
totic pathways may explain the pathogenesis of a number of chronic lung diseases [37]. Our interest in IL13 induction of genes responsible for an apoptotic process in the lung stemmed from preliminary studies, where IL13-induced cytotoxicity in tumor cell lines via its ability to up-regulate proapoptotic and down-regulate antiapoptotic factors in these cells [15]. The TNF $\alpha$ related proapoptotic factor TRAIL is a potent inducer of fibroblast apoptosis by induction of a number of proapoptotic factors, especially caspase 9 [38].

IL13 is a pleiotropic cytokine with remarkable effects in the newborn lungs. Overexpression of IL13 causes macrophage, lymphocyte and eosinophILrich pulmonary inflammatory response, mucus metaplasia, crystal deposition, subepitelial fibrosis and alveolar enlargement in MAS. The majority of alveoli are formed by developmental process that occurred at birth and we not sure whether alveolar enlargement is due to alterations in alveolar development or due to the destruction of already normally formed alveoli. However, results with adult rabbits also showed alveolar enlargement. These results demonstrate, that alveolar enlargement is a short term lung response to injury but lung fibrosis require more extensive periods of time. We believe that injuries effect of IL13 involved a production of ANG II and ACE inhibitor Captopril should significantly decrease its injuries effect. Captopril inhibits conversion of ANGEN to ANG II and consequently apoptosis formation. IL13 is also is a strong activator of tissue proteolysis [25].

Blockage of serine or cysteine proteases has remarkably ameliorated the effects of IL13 induced lung inflammation and apoptosis. The effect of cysteine protease inhibitors, serpins, on IL13 effect was also evaluated. Serpins abrogated the IL13-induced lung inflammatory response [25]. Serpins also were able to significantly reduce IL13 induced increase in lung volume and alveolar size. They reduce IL13 induced lung and lavage cell inflammation.

Our findings demonstrate the impact of IL13 on the alveolar cells, lung injury and potentially on lung fibrosis. The responses of alveolar cells to the expression of IL13 suggest that these cells could be targeted with an anti-IL13 antibody [39]. It is very possible that its antibodies and other inhibitors may be important in preventing a MAS and consequent lung fibrosis.

\section{CONCLUSIONS}

We have demonstrated elevated expression of the inflammatory cytokine IL13 in meconium-instilled two week old rabbit pups' lungs. We also showed that pretreatment with Captopril significantly decreased meconium-induced expression of IL13 cytokine as well as meconium-induced lung injury and apoptosis. This find- ing suggests that the mechanism of IL13 induced lung injury is similar to that caused by TNF $\alpha$, IL6 and IL8 cytokine mechanisms.

\section{ACKNOWLEDGEMENTS}

We are grateful for a support of Dr. Garry Kruh, UIC Cancer Center Director, who unexpectedly left us earlier this year as a result of a tragic death.

We also thank Dr. Beck and Dr. Ozer who secured an opportunity to complete a several projects after this happens.

We thank Huali Dong, Islam Shariful and Derrik Jordan for a wonderful technical and supportive assistance.

\section{REFERENCES}

[1] Vidyasagar, D., Uhal, B., Bhat, R., Navale, S. and Zagariya, A. (2004) The TNF $\alpha$, IL1 $\beta$, IL6, IL8, IL10 and INGg cytokine expression in meconium-instilled newborn lungs. Indian Journal of Pediatrics, 71, 195- 102.

[2] Wisnievsky, M., Zagariya, A., Pavuluri, N., Shrinivasan, H., Navale, S. and Vidyasagar, D. (2005) Meconium induces injury in anoxic isolated perfused rat lungs. Pediatric Pulmonology, 39, 368-373.

[3] Vidyasagar, D., Lukkarinen, H., Kaapa, P. and Zagariya, A. (2005) Inflammatory responce and apoptosis in newborn lungs after meconium aspiration. Biotechnology Progress, 21, 192-197. doi:10.1021/bp0497886

[4] Zagariya, A., Bhat, R., Uhal, B., Navale, S. and Vidyasagar, D. (2005) Apoptosis of airway epithelial cells in response to meconium. Life Sciences, 76, 1849-1858. doi:10.1016/j.lfs.2004.10.033

[5] Zagariya, A., Bhat, R., Uhal, B., Navale, S., Freidine, M. and Vidyasagar, D. (2000) Cell death and lung cell histology in meconium aspirated newborn rabbit lung. European Journal of Pediatrics, 159, 819-826. doi:10.1007/s004310000581

[6] Zagariya, A., Bhat, R., Navale, S. and Vidyasagar, D. (2006) Inhibition of meconium-induced cytokine expression by Captopril. Pediatrics, 117, 1722-1727. doi:10.1542/peds.2005-0274

[7] Lukkarinen, H., Laine, J., Aho, H., Zagariya, A., Vidyasagar, D. and Kaapa, P. (2004) Angiotensin II receptor blockade inhibits pneumocyte apoptosis in experimental meconium aspiration. Pediatric Research, 55, 326-333. doi:10.1203/01.PDR.0000100901.88697.66

[8] Uhal, B.D., Wang, R., Laukka, J., Zhyang, J., SoledadConrad, V. and Filippatos, G. (2003) Inhibition of amiodarone-induced lung fibrosis but not alveolitis by angiotensin system antagonists. Pharmacology \& Toxicology, 92, 81-87. doi:10.1034/j.1600-0773.2003.920204.x

[9] Doucet, C., Brouty-Boye, D., Pottin-Clemenceau, C., Canonica, G.W., Jasmin, C. and Azzarone, B. (1998) Interleukin (IL) 4 and IL13 act on human lung fibroblasts. Implication in asthma. Journal of Clinical Investigation, 101, 2129-2139. doi:10.1172/JCI741

[10] Murata, T., Orobi, N.I., Debinski, W. and Puri, R.K. (1997) Structure of IL13 receptor: Analysis of subunit composition in cancer and immune cells. Biochemical and Biophysical Research Communications, 238, 90-94. 
doi:10.1006/bbrc.1997.7248

[11] Toru, H., Pawankar, R., Ra, C., Yata, J. and Nakahata, T. (1998) Human mast cells produce IL13 by high-affinity IgE receptor cross-linking: Enhanced IL13 production by IL4 primed human mast cells. Journal of Allergy and Clinical Immunology, 102, 491-502. doi:10.1016/S0091-6749(98)70140-X

[12] Murata, T., Hussain, S.R., Mohri, H. and Puri, R.K. (1998) Two different receptor chains are expressed in normal human skin fibroblasts, and IL4 and IL13 mediate signal transduction through a common pathway. International Immunology, 10, 1103-1110. doi:10.1093/intimm/10.8.1103

[13] Brombacher, F. (2000) The role of interleukin 13 in infectious disease and allergy. BioEssays, 22, 646-656. doi:10.1002/1521-1878(200007)22:7<646::AID-BIES7> 3.0.CO;2-9

[14] Wills-Karp, M., Luyimbazi, J., Xu, X., Schofield, B., Neben, T.Y., Karp, C.L. and Donaldson, D.D. (1998) Interleukin IL13: Central mediator of allergic astma. Science, 282, 2258. doi:10.1126/science.282.5397.2258

[15] Kawakami, M., Kawakami, K. and Puri, R.K. (2002) Apoptotic pathways of cell death induced by an interleukin-13 receptor-targeted recombinant cytotoxin in head and neck cancer cells. Cancer Immunology, Immunotherapy, 50, 691-700. doi:10.1007/s00262-001-0242-6

[16] Belperio, J.A., Dy, M., Burdick, M.D., Xue, Y.Y., Li, K.J.A. and Elias, M.P. (2002) Keane Interaction of IL13 and $\mathrm{C} 10$ in the pathogenesis of bleomycin-induced pulmonary fibrosis. American Journal of Respiratory Cell and Molecular Biology, 27, 419.

[17] Oriente, A., Fedarko, N.S., Pacocha, S.E., Hugan, S.K., Lichtenstein, L.M. and Essayan, D.M. (2000) Interleukin 13 modulates collagen homeostasis in human skin and keloid fibroblasts. Journal of Pharmacology and Experimental Therapeutics, 292, 988-994.

[18] Chiaramonte, M.G., Donaldson, D.D., Cheever, A.W. and Wynn, T.A. (1999) An IL13 inhibitor blocks the development of hepatic fibrosis during a T-helper type 2-dominated inflammatory response. Journal of Clinical Investigation, 104, 777. doi:10.1172/JCI7325

[19] Chiaramonte, M.G., Donaldson, D.D., Cheever, A.W. and Wynn, T.A. (1999) An IL13 inhibitor blocks the developmnt of hepatic fibrosis during a T-helper type 2-dominated inflammatory responce. Journal of Clinical Investigation, 104, 777-785. doi:10.1172/JCI7325

[20] Jakubzik, C., Kunkel, S.L., Joshi, B., Puri, R. and Hogaboam, C. (2002) Interleukin-13 fusion cytotoxin arrests Schistosoma mansoni Egg-induced pulmonary granuloma formation in mice. The American Journal of $\mathrm{Pa}$ thology, 161, 1283-1297. doi:10.1016/S0002-9440(10)64405-7

[21] Zuo, F., Kaminski, N., Eugui, E,, Allard, J., Yakhini, Z., Ben-Dor, A., Lollini, L., Morris D., Kim, Y. and De Lustro, B. (2002) Gene expression analysis reveals matri-lysin as a key regulator of pulmonary fibrosis in mice and humans. Proceedings of the National Academy of Sciences, 99, 6292. doi:10.1073/pnas.092134099

[22] Evanoff, H., Burdick, M.D., Moore, S.A., Kunkel, S.L. and Strieter, R.M. (1992) A sensitive ELISA foe the detection of human monocyte chemoattractant protein-1 (MCP-1). Immunological Investigations, 21, 39-49.

\section{doi:10.3109/08820139209069361}

[23] Graves, P.E., Kabesch M., Halonen, C.J., Holberg, M., Baldini, C., Fritzsch, S.K., Weiland, R.P., Erickson, E. and Martinez, F.D. (2000) A cluster of seven tightly linked polymorphism in the IL13 gene is associated with total serum IgE levels in three populations of white children. The Journal of Allergy and Clinical Immunology, 105, 506-513. doi:10.1067/mai.2000.104940

[24] Uhal, B.D., Gidea, C., Bargout, R., Bifero, A., IbarraSunga, O., Papp, M., Flynn, K. and Filippatos, G. (1998) Captopril inhibits apoptosis in human lung epithelial cells: A potential antifibrotic mechanism. American Journal of Physiology, 275, L1013-L1017.

[25] Zheng, T., Zhu, Z., Wang, Z., Homer, R.J., Ma, B., Riese, R.J., Chapman, H.A., Shapiro, S.D. and Elias, J.A. (2000) Inducible targeting of IL13 to the adult lung causes matrix metalloproteinase- and cathepsin-dependent emphysema. Journal of Clinical Investigation, 106, 1081-1093. doi:10.1172/JCI10458

[26] Gordon, S. (2003) Alternative activation of macrophages. Nature Reviews Immunology, 3, 23. doi:10.1038/nri978

[27] Carre, P.C., Mortenson, R.L., King, T.E., Noble, P.W., Sable, C.L. and Riches, D.W. (1991) Increased expression of the interleukin-8 gene by alveolar macrophages in idiopatic pulmonary fibrosis. Journal of Clinical Investigation, 88, 1802. doi:10.1172/JCI115501

[28] Matrinet, Y., Rom, W.N., Grotendorst, G.R., Martin, R.G. and Crystal, R.G. (1987) Exagerated spontaneous release of plateled-derived growth factor by alveolar macrophages from patients with idiopatic pulmonary fibrosis. The New England Journal of Medicine, 317, 202. doi:10.1056/NEJM198707233170404

[29] Smith, R.E., Strieter, R.M., Zhang, K., Phan, S.H., Standiford, T.J., Lukacs, N.W. and Kunkel, S.L. (1995) A role for C-C chemokines in fibrotic lung disease. Journal of Leukocyte Biology, 57, 782.

[30] Lee, C.G., Homer, R.J., Zhu, Z., Lanone, S., Wang, X., Koteliansky, V., Shipley, J.M., Gotwals, P., Noble, P. Chen, Q., Senior, R.M. and Elias, J.A. (2001) Interleukin IL13 induces tissue fibrosis by selectively stimulating and activating transforming factor beta(1). The Journal of Experimental Medicine, 194, 809-821. doi:10.1084/jem.194.6.809

[31] Oriente, A., Fedarko, N.S., Pacocha, S.E., Huang, S.K., Lichtenstein, L.M. and Essayan, D.M. (2000) Interleukin IL13 modulated collagen homeostasis in human skin and keloid fibroblasts. Journal of Pharmacology and EXperimental Therapeutics, 292, 988-994.

[32] Kunkel, S.L., Lukacs, N.W., Strieter, R.M. and Chensue, S.W. (1996) Th1 and Th2 responces regulate experimental lung granuloma development. Sarcoidosis, Vasculitis and Diffuse Lung Diseases, 160, 481-490.

[33] McKenzie, A.N., Culpepper, J.A., de Malefut, W., Briere, F., Pummonen, J., Aversa, G., Sato, A., Dana, W., Cocks, B.G. and Menon, S. (1993) Interleukin IL13, a T-cell-derived cytokine that regulates human monocyte and B-cell function. Proceedings of the National Academy of Sciences, 90, 3735. doi:10.1073/pnas.90.8.3735

[34] Burd, P.R., Thompson, W.C., Max, E.E. and Mills, F.C. (1995) Activated mast cells produce interleukin IL13. The Journal of Experimental Medicine, 181, 1373. doi:10.1084/jem.181.4.1373 
[35] Hancock, A., Armstrong, L., Gama, R. and Millar, A. (1998) Production of interleukin IL13 by alveolar macrophages from normal and fibrotic lungs. American Journal of Respiratory Cell and Molecular Biology, 18, 60.

[36] Hancock, A., Armstrong, L., Gama, R. and Millar, A. (1998) Production of interleukin 13 by alveolar macrophages from normal and fibrotic lung. American Journal of Respiratory Cell and Molecular Biology, 18, 60.

[37] Fine, A., Janssen-Heininger, Y., Soultanakis, R.P., Swisher, S.G. and Uhal, B.D. (2000) Apoptosis in lung pathophysi- ology. American Journal of Physiology, 279, L423-L427.

[38] Soengas, M.S., Alarcon, R.M., Yoshida, H., Giaccia, A.J., Hakem, R., Mak, T.W. and Lowe, S.W. (1999) Apaf-1 and caspase 3 in p53-dependent apoptosis and tumor inhibition. Science, 284, 156-159. doi:10.1126/science.284.5411.156

[39] Puri, R.K. (2001) Cytotoxins directed at interleukin-4 receptors as therapy for brain tumors. Methods in $\mathrm{Mo}-$ lecular Biology, 166, 155-176. 